\title{
Facial expressions and the mental status of patients receving cosmetic treatment
}

\author{
Natalya Nikolayeva', Tatyana Terekhova², Andrey Yakubovich¹, Igor Seminskiy, \\ Oksana Tirskaya ${ }^{1}$, Svetlana Byvaltseva1, Aleksandr Chashchin ${ }^{1}$ \\ ${ }^{11}$ rkutsk State Medical University, Irkutsk, Russian Federation \\ ${ }^{2}$ rkutsk State University, Irkutsk, Russian Federation
}

\begin{abstract}
Objectives. This study explores changes in facial expression and the mental status of patients after cosmetic procedures, specifically after the facial injection of Botulinum toxin type A.

Materials and methods. The research sample includes 40 females and each was offered a questionnaire form individually before and after the cosmetic procedure (on 14-21 day follow-up, the full-effect period). The standard dose of botulinum A toxin was injected intramuscularly into the muscles of the upper third of the face to smooth out the forehead wrinkles, frown lines, and the crow's feet.

Outcome. The Prokhorov's Mental Health Inventory in this study identifies the mental status of patients and data are processed using the Wilcoxon signed-rank test. Higher doses of Botulinum toxin type A relax muscles and thus, smooth out the wrinkles. However, female patients experience problems with eyebrow contraction afterwards. After the cosmetic procedure, the patient's true feelings and emotions became difficult to determine. As revealed, the given cosmetic intervention has a negative impact on the mental state of a female patient. The survey demonstrates changes in mood towards sadness, sorrow, drowsiness, negative intentionality and generally heavy feelings.

Conclusions. Facial expression not only transmit the subject's experiences into the external environment (communicative message) but also influences mental processes and personal states through feedback. In the second case, it is the key to sensory cognition and emotional self-monitoring. The language of facial expression prevents the pathological effects of psycho-emotional stress from developing and contributes to person's adaptation.
\end{abstract}

Keywords: facial expression, mental health profile, sensory cognition, Botulinum toxin type A, personality, communication, paramimia, emotions

\section{INTRODUCTION}

Today, emotional expressions as the outward signals of inner feelings are of interest to not only psychologists and psychiatrists but also cosmetologists who apply new techniques of facial rhytids effacement. One of such procedures is the botulinum toxin type A (BT-A) injections for correction of facial wrinkles. Recent statistics show that these injections account for 3.2 million of all cosmetic procedures per year. According to the United States, BT-A injections make up $81 \%$ of all anti-aging procedures (1). Botulinum toxin type A injection is the most common cosmetic procedure globally. Surveys from core aesthetic specialty organizations consistently rank it first on lists of member-reported, nonsurgical aesthetic procedures. In 2014, the
American Society for Aesthetic Plastic Surgery reported more than 3.5 million botulinum toxin procedures (2). The International Society of Aesthetic Plastic Surgery survey reported more than 4.8 million procedures worldwide in 2014 (3) and the 2013 American Society for Dermatologic Surgery survey found a 20 percent increase compared with 2012 (4). Similar trends are reported in Europe and Asia (5).

Drugs with BT-A are muscle relaxants and belong to the group of peripherally acting agents. The BT-A is a protein molecule with a heavy (molecular weight of $100.000 \mathrm{Da}$ ) and light (molecular weight of 50.000 Da) chain held together by a heat-labile disulfide bond. A heavy chain has a high affinity for binding to specific receptors located on the surface of target 
neurons. The light chain is a $\mathrm{Zn} 2+$ dependent protease, which activity is specific to cytoplasmic sites of a synaptosomally bound protein (molecular weight of $25.000 \mathrm{Da}$; SNAP-25, protein of exocytosis). At the first stage of action, BT-A forms a specific bond between the molecule and the presynaptic membrane. This process takes 30 minutes. The second stage is the penetration of the bound toxin into the neuronal cytosol through endocytosis. The intracellular light chain acts as a Zn2+ dependent cytosol protease - selectively breaks down SNAP25 , which at the third stage, results in a blockade of acetylcholine release at presynaptic terminals of cholinergic neurons. The process is completed with persistent chemodenervation (6).

The intramuscular administration of BT-A interferes with the extrafusal muscle fibers through the inhibition of alpha-motoneurons at the neuromuscular synapse; and with the muscle spindles through the inhibition of gamma-motoneuron cholinergic synapse on the intrafusal fiber. The reduction in gamma activity leads to the relaxation of intrafusal fibers that constitute the muscle spindle and reduces the activity of 1a-afferents. This leads to a decrease in the activity of muscle receptors of stretching, as well as to the efferent activity of alpha and gamma motoneurons. Clinically, this manifests as the pronounced relaxation of the injected facial muscles $(7 ; 8)$.

Hence, the BT-A-induced chemical denervation in mimic muscles disturbs the transmission of impulses from the central to the peripheral nervous system and vice versa. Technically, this is a manifestation of distress (9).

The demand for this procedure among patients can be explained by:

1. an artificial need for BT-A injections, formed through advertising. An advertisement draws the attention of women to a negative attitude towards facial wrinkles and lines and then offers an easy way to remove them. This strategy is simply a manipulation. Fifteen years ago, many patients in Russia did not consider mimic wrinkles important and knew nothing about the botulinum toxin or the socalled "elixir of youth" (10);

2. a desire to "fit in"; passive agreement with the opinions and attitudes that exist in society, since botulinum toxin injections are associated with "the state of being young", as well as with a successful and happy life (11);

3. a visible effect of mimic wrinkles being smoothed out (12).

In parallel to the demand for BT-A treatment, many questions arise. Is there a necessity to remove facial wrinkles? Is it safe? How will this affect facial expression?

In cosmetology, there are many studies devoted to the safety of botulinum toxin type A (13). Researches focus on the blepharoptosis, brow ptosis, systemic effects of botulinum toxin on the body, etc. However, they draw very little attention to changes in facial expression that occur in patients after the BT-A injections.

Indications for BT-A treatment are facial wrinkles, located mainly in the upper third of the face (for the lower third, cosmetologists may use other drugs) - on the frown line, crow's feet (lines around the outer corners of the eyes), and on the forehead lines. The treatment procedure is as follows: a solution of botulinum toxin is administered intramuscularly with an insulin syringe into the muscles under the wrinkles. These dynamic expression lines form perpendicular to muscle fiber contraction (14).

Cosmetologists and patients believe that generally, botulinum toxin does not affect the emotional state of a person or, more specifically, the emotion facial expression, in spite of its movement-restricting effect on facial muscles (15). The current results show that the size of the negative effect of treating the crow's feet appears to be similar in size to the positive effect of treating the frown lines and so for people having both treatments there is no net drop in $\operatorname{mood}(16,17)$.

Volov (18) states that "facial expression is a unique psycho-physiological phenomenon that reflects both sensual and cognitive experience and the person's character through a simple psychomotor action" $(18,211)$. Thus, facial expression supervenes on the mental content. Facial mobility as an instrument to express emotions relates to most crucial mental processes, as compared to gestures, because people do facial expressions both inside and outside communication (e.g. when reflecting upon past events; when resonating with passing situations or meaningful memories. The bodily sensations that originate from the contraction of facial muscles are associated with specific psycho-emo- 
tional reactions. Facial expression patterns linked to the emotional response provide information about the status of an individual during the passing event and thus lay ground for sensory cognition $(18,213)$. Occasionally, distressed patients with a sympathetic drive are able to something within themselves that subsequently causes damage to their state of emotions.

Silvan Tomkins, G.N. Gellhorn and Carroll Ellis Izard emphasize the mimic origin of emotions. The muscular system of the face is unique - it is well-differentiated and the speed of its responses is close to that in which emotions appear. Thus, Izard states that the facial feedback is responsible for the introspective awareness of emotions and changes in the facial muscles have a strong encouraging effect on mental functions $(19,90)$.

Tomkins indicates that facial expressions following a specific emotion provoke the formation of a specific feeling and transmit it in the form of a mimic code (communicative message) (20). Facial expression is undoubtedly important for human communication. It helps to create an emotional context of communication, to identify the emotional status of another partner in conversation, his/her attitude towards the fact of communication, real motives and hidden intentions.

Labunskaya rises the matter of facial expression as a form of self-approval. According to her, emotions and their external manifestations are a "form of existence", a part of mental phenomena, which largely agrees with the Russian tradition of considering emotional expression a link between self and non-self (21).

Facial expression is indisputably one of the factors of female attractiveness (22).

Despite the adaptation significance of facial expression, recent years are fraught with evidence on the negative effect of cosmetic wrinkle correction on the natural emotional expression. In the search to remove facial wrinkles, patients ignore the role of expression muscles in the formation and expression of emotions, in sensory cognition, communication, and in adaptation.

A face without an expression is considered a beauty standard. The credibility of this statement and the ultimate price of following it are matters yet to be resolved. With this regard, analyzing features of facial expression in females after BT-A in- jections is of interest because the mechanism of BT-A action is associated with the chemical muscle denervation.

This study attempts to answer the following: Do patients change in mental status after BT-A injections?

Therefore, the purpose of this article is to study changes in facial expression and the psychological status of women, who underwent cosmetic treatment, specifically the BT-A administration.

\section{MATERIAL AND METHODS}

The mental status assessment was conducted among women interested in BT-A wrinkle correction, with their consent, before and after BT-A injections to muscles of the upper third of the face. The assessment was performed using the self-report Prokhorov's Mental Health Inventory (hereinafter referred to as the Inventory; Appendix 1). This is a 40 -item staple scale questionnaire survey that covers four domains of psychological state: mental processes (10 questions), physiological reactions (10 questions), feelings (10 questions), and behavior (10 questions). Indicators within each category range from " -5 " to " 5 ".

The Inventory is designed to evaluate the psychological experience of a subject from the perspective of individual components (i.e., behavioral and cognitive characteristics) within the mental health profile. Prokhorov believes that any psychological or mental status can be described through the person's functioning.

The research sample includes 40 females and each was offered a questionnaire form individually before and after the cosmetic procedure (on 14-21 day follow-up, the full-effect period). The standard dose of botulinum A toxin was injected intramuscularly into the muscles of the upper third of the face to smooth out the forehead wrinkles, frown lines, and the crow's feet.

This research has been approved by the IRB of the authors' affiliated institutions.

\section{DATA ANALYSIS}

Data were double-entered into Origin 9.1. The analysis was performed using STATA 12.0 (StataCorp LP, USA). The statistical data analysis were carried out using the Wilcoxon signed-rank test. 


\section{Data processing procedure}

Once the questionnaires are filled out, that is initially, scores for items within domain are converted to an 11-point scale so that the scores "-5", "-4", "-3", "-2", “-1", "0", “1”, “2”, “3", “4”, “5” become as follows: “1”, “2”, “3”, “4”, “5”, “6”, “7”, “8”, “9”, “10”, "11", respectively. The domain-average score relates to the extent to which behavioral and cognitive characteristics within the mental health profile are expressed. The obtained results form a framework for the graphical representation of the mental status of patients in the form of histograms (Figure 1).

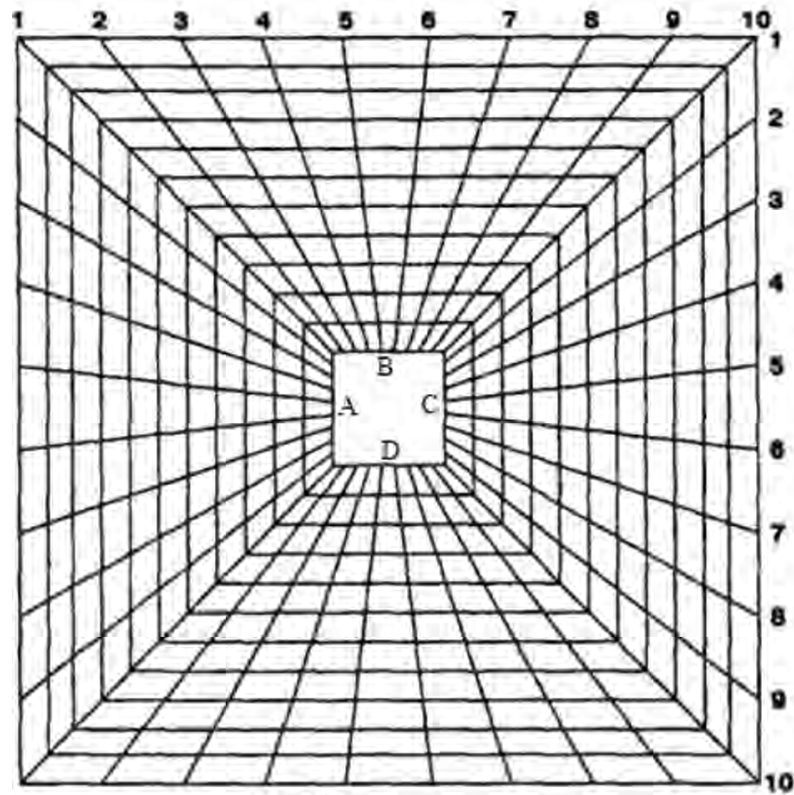

FIGURE 1. Mental Status Matrix: edges - scores; isohypses - severity degrees (on the l-point scale). Note: $A$ - mental processes; $B$ - physiological reactions; $C$ - feelings; $D$ - behavior.

\section{RESULTS}

Correlation between facial expression and BT-A treatment

To treat vertical wrinkles in the glabellar area, BT-A is injected into the corrugator supercilii (Figure 2a). The effect from BT-A (muscle relaxation) makes the wrinkles smooth out. When this happens, the patient becomes restricted in the ability to contract her eyebrows (Figure 3a). This suggests the impairment of a muscle function by corrugator supercilii, which draws eyebrows downward and medially thus enabling the expression of emotions like fear, anger, interest, dissatisfaction, etc.

In another case, BT-A is injected into the venter frontalis musculi epicranii (or the frontal belly of ep- icranius muscle, also known as the frontalis muscle) to correct horizontal forehead wrinkles (Figure $2 b$ ).

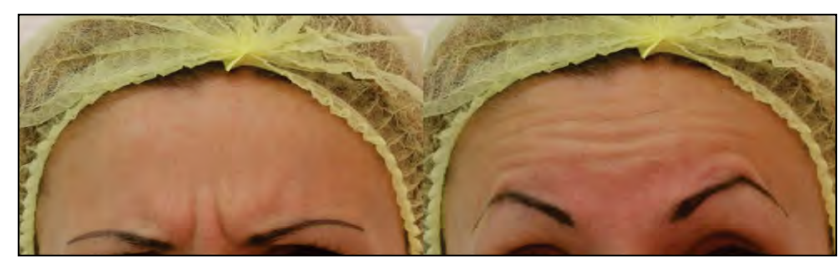

FIGURE 2. Female Patient $X$ before BT-A Injection: a) corrugator supercilii muscle contraction (frown photo); b) frontalis muscle contraction (eyebrow raising photo)

This intervention interferes with the function of the frontalis muscle, which, when contracts, raises the eyebrows up and enables the expression of surprise, joy, interest, fear, etc. Figure 3 shows facial expression photos of a female patient after the administration of the Botulinum A toxin. The patient can neither lower her eyebrows nor raise them. Accordingly, this patient will have problems expressing emotions and the cause of these problems is the BT-A-induced chemical denervation of muscles.

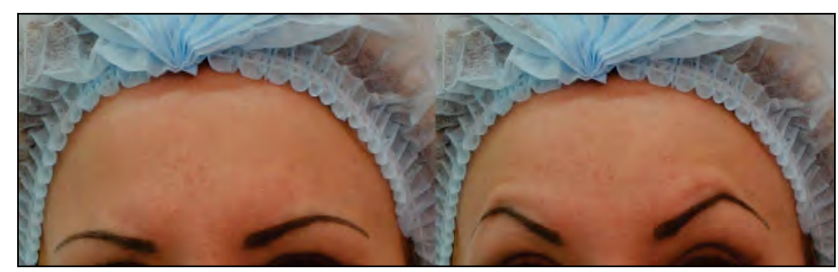

FIGURE 3. Female Patient $X$ after BT-A Injection: a) corrugator supercilii muscle contraction (frown photo); b) frontalis muscle contraction (eyebrow raising photo)

From the before photo of a frowning patient (Figure $4 a)$, one can identify her emotional state without difficulty, as the view of her lowered eyebrows is distinct. From the after photo (Figure 4b), it is rather difficult to determine the true feelings of the patient. The patient attempts to move her eyebrows downward but the medial brows, unlike the lateral brows, do not move and so that the eyebrow curves look unnatural. The activity in the frontalis muscle also changed alongside the activity in muscles around the eyes and in muscles of the middle third of the face (compensatory increment).

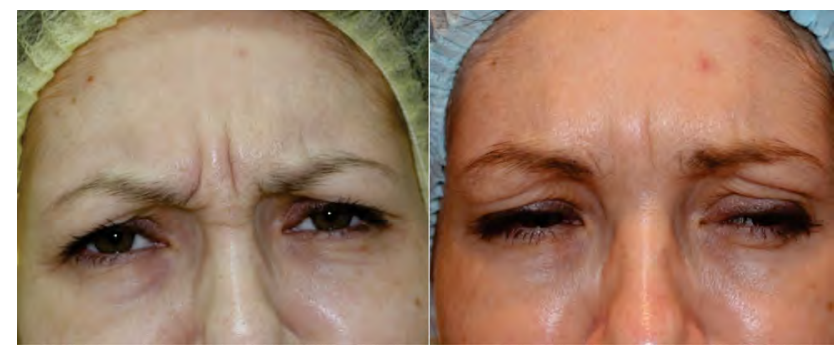

FIGURE 4. Frown Lines: a) before photo (natural expression); b) after photo 
The above examples demonstrate changes in the facial expression of patients after the mimic wrinkle correction using the Botulinum toxin type A.

The research claim is that aside from changes in the facial expression, patients may experience a change in their emotional state. Below are the Prokhorov's Inventory findings.

Correlation between psychological status and BT-A treatment

On the "mental processes" scale, statistically significant differences are found in items, such as:

- perception (shift towards lower susceptibility to external influences);
- memory (shift towards memory recall/retrieval difficulties);

- imagination (shift towards difficulty in producing ideas, towards caged imagination);

- emotions (the emergence of anxiety, fear, hopelessness, and despair) (Figure 5).

On the "physiological reactions" scale, statistically significant differences are found in the status of oral mucosa (Figure 6): "dry feeling in the mouth" drops a few points after the cosmetic procedure.

Most of statistically significant differences are found on the "feelings" scale: sadness/optimism, sorrow/fervency, drowsiness/vivacity, negative/positive intentionality, heavy feelings/light feelings $(\mathrm{p}<0.01)$.

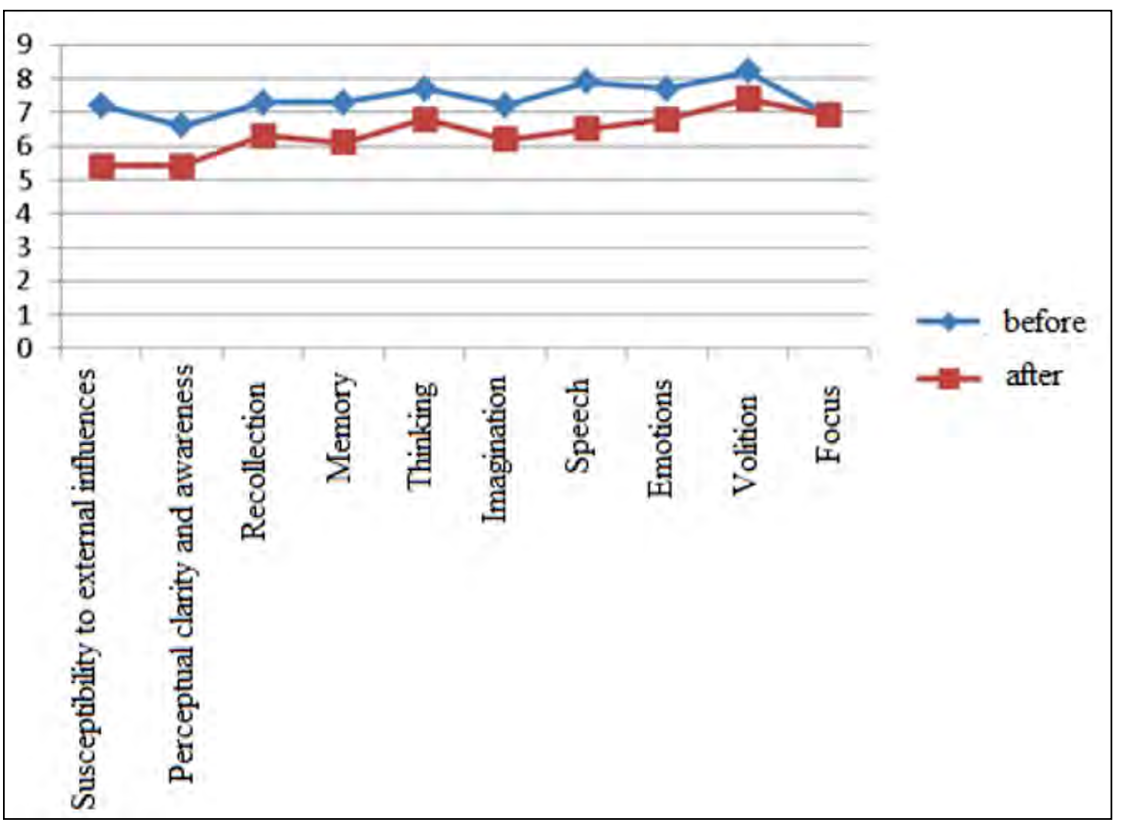

FIGURE 5. Ratings on Mental Processes Scale Before and After BT-A Treatment

Note: Significance values show the simple comparisons before and after treatment $(p<0.01)$.

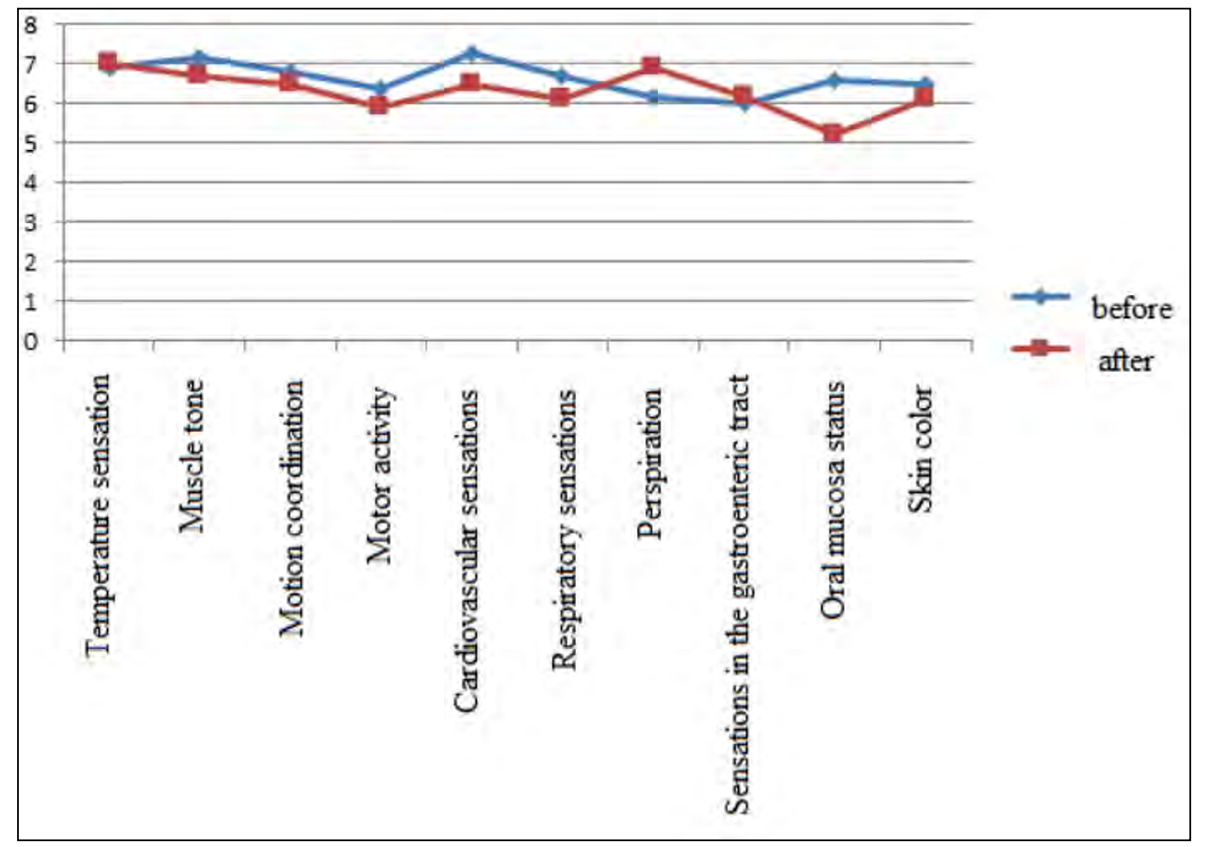

FIGURE 6. Ratings on Physiological Reactions Scale Before and After BT-A Treatment

Note: Significance values show the simple comparisons before and after treatment $(p<0.01)$. 


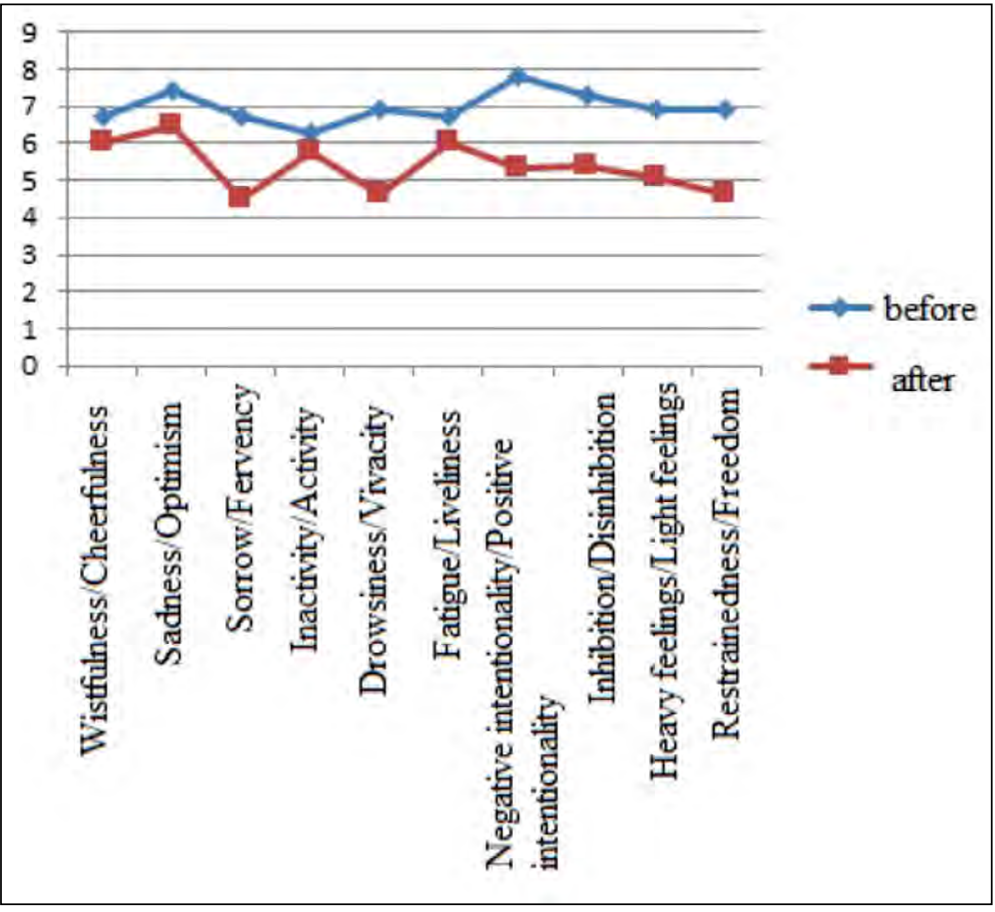

FIGURE 7. Ratings on Feelings Scale Before and After BT-A Treatment

Note: Significance values show the simple comparisons before and after treatment $(p<0.01)$.
The survey demonstrates changes in mood towards sadness, sorrow, drowsiness, negative intentionality and generally heavy feelings.

Statistically significant differences on the "behavior" scale (non-driven/driven, spontaneous/deliberate, insecure/confident) also demonstrate a negative correlation $(p<0.01)$. Changes can be observed towards non-driven, impulsive, and insecure behavior.
Thus, findings show a change in the core items of the mental health profile among women after the administration of botulinum toxin type A into the facial muscles of the upper third of the face. Subsequent to the procedure, females have the experience of emotional tension, hesitation, etc. From the viewpoint of the cosmetologist, however, the procedure outcome meets the requirements and is not fraught with complications.

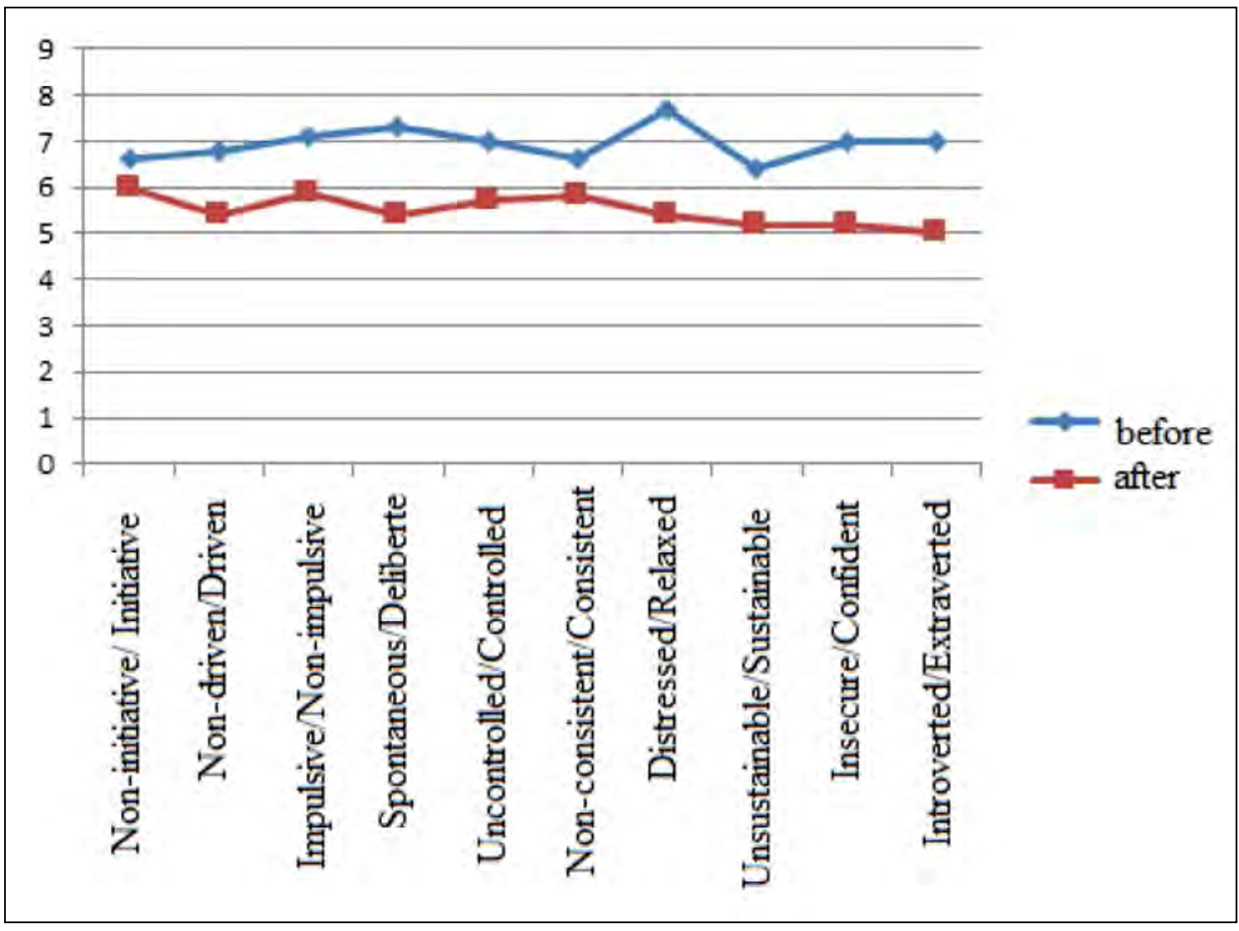

FIGURE 8. Ratings on Behavior Scale Before and After BT-A Treatment

Note: Significance values show the simple comparisons before and after treatment $(p<0.01)$. 


\section{DISCUSSION}

Changes in the mental status of women who received BT-A treatment, as well as before and after pictures of facial expression, indicate a correlation between inner experiences and their embodiment.

Lewis explores the emotional state further by looking at the effect that BT-A treatment of crow's feet has on the mood. This treatment involves injections into the orbicularis oculi muscles and leads to a reduction in facial lines, also called as laughter lines. Based on embodied emotions, it was predicted that treating the laughter lines would lead to a lowering of a person's mood. It happened that all of the participants who were BT-A treated for crow's feet were also BT-A treated for frown lines. The contrast between those people who received BT-A for frown lines and those people who received the treatment for both frown lines and crow's feet shows that the effect of having a treatment for crow's feet is to increase depression and anxiety scores relative to those who had only received the frown lines treatment (16). The most attention driven change is the effect of crow's feet treatment using BT-A injections in the orbicularis oculi muscles. Such an intervention leads to a chemical denervation of the palpebral portion of orbicularis oculi muscle responsible for a Duchenne smile (20). At that, a patient reaches a long-lasting effect but loses the ability to smile using the eye muscles (23). Thus, BT-A interferes with the process of embodying feelings like joy and interest by leaving undisturbed only the muscles of the middle and lower third of the face to make a smiling facial expression (24).

The immobilized facial muscles restore through 3to 6-month reinnervation. Until then, facial expression remains unnatural to varying extent.

The facial expression muscles do not have fasciae, which often contribute to BT-A diffusion to the adjacent muscles. Therefore, facial mimicry here is somewhat simplified. Of course, emotional expression involves more than one mimic muscle and thus detriment in the function of some muscles entails the activation of other muscles to compensate this change, which reduces the negative effect but dos not remove the consequences completely.

Another feature worth mentioning is paramimia.

According to the glossary of psychiatric terms, paramimia refers to facial mimicry inadequate to or not congruent with patient's emotions or the situation (25). Paramimia may be a symptom of brain pathology or mental illness (e.g., schizophrenia).

The examples of non-consistency between what the BT-A treated patient is experiencing and what her face expresses after chemical denervation are also known in the cosmetic practice. However, this non-consistency is clearly not a symptom of disease but a result of medical intervention. The theory explaining why treating crow's feet lowers mood is the same as that explaining why treatment of glabellar frown lines improves it. The strength of the facial feedback that a person would get when smiling would therefore be reduced relative to an untreated person and hence they feel less happy even when smiling $(26 ; 27)$. The current results show that the size of the negative effect of treating the crow's feet appears to be similar in size to the positive effect of treating the frown lines and so for people having both treatments there is no net drop in mood (16).

From the perspective that facial mimicry is important in emotional expression decoding, the current study shows that a loss of mobility in the face as a result of BT-A injections is related to a loss in emotional-expression recognition ability. This effect had been shown previously but in an experiment that only assessed emotion recognition from the mouth region. Therefore, it remained unclear as to whether whole face emotion recognition would be similarly affected.

The current study demonstrates that the cosmetic effects from BT-A can also include a wide array of psychological effects. Results reported by other researchers demonstrate that BT-A treatment leads to a decreased mood in cosmetic patients $(14 ; 12 ; 28)$. The mental status here includes, by contrast, a broader range of effects, including physiological reactions, feelings, behaviors, and emotions. At that, facial expression of emotions plays a role in the transmission of personal experience (communicative message) and the facial feedback influences mental processes and adaptation abilities of a person thereby leaving an imprint on personality.

\section{CONCLUSIONS}

The current study reveals that a BT-A treated patient has problems with the emotion expression due chemodenervation. Findings demonstrate negative changes in the mental state of women after the admin- 
istration of BT-A into the mimic muscles of the upper third of the face. Most of statistically significant differences are found on the "feelings" scale: sadness/ optimism, sorrow/fervency, drowsiness/vivacity, negative/positive intentionality, heavy feelings/light feelings $(p<0.01)$. Changes in mood are found to be towards sadness, sorrow, drowsiness, negative intentionality and generally heavy feelings. Least of statistically significant differences are found on the scale "physiological reactions". Among them, the dry feeling in the mouth after the procedure.

\section{Appendix 1}

The Prokhorov's Mental Health Inventory

Put a name to what you are experiencing at the time of filling out the questionnaire (e.g., joy or anxiety, etc.). Afterwards, rate your experience on the scale from very low level (-5) to very high level (5), with " 0 " representing the normal (unchanged) mental status. You may cross out no more than one number and remember - there are neither good nor bad answers.

\begin{tabular}{|c|c|}
\hline \multicolumn{2}{|c|}{ MENTAL PROCESSES } \\
\hline \multicolumn{2}{|l|}{ 1. Perception. Susceptibility to external influences } \\
\hline Decreasing to not susceptible & Increasing to elevated \\
\hline \multicolumn{2}{|c|}{$-5-4-3-2-1012345$} \\
\hline \multicolumn{2}{|l|}{ 2. Perception. Clarity and perceptual awareness } \\
\hline Decreasing, blurred, with poor clarity and low awareness & Conscious, with high clarity \\
\hline \multicolumn{2}{|c|}{$-5-4-3-2-1012345$} \\
\hline \multicolumn{2}{|l|}{ 3. Perceptual recollection } \\
\hline Recollection difficulty & Clear, with the ease of retrieval effect \\
\hline \multicolumn{2}{|c|}{$-5-4-3-2-1012345$} \\
\hline \multicolumn{2}{|l|}{ 4. Memory } \\
\hline Poor, with difficulty in remembering, recall/retrieval problems & Enhanced; better remembering and recall skills \\
\hline \multicolumn{2}{|c|}{$-5-4-3-2-1012345$} \\
\hline \multicolumn{2}{|l|}{ 5. Thinking } \\
\hline Slow, with difficulty in understanding and reasoning & Fast; enhanced understanding and reasoning skills \\
\hline \multicolumn{2}{|c|}{$-5-4-3-2-1012345$} \\
\hline \multicolumn{2}{|l|}{ 6. Imagination } \\
\hline Caged, with difficulty in producing ideas & Good, beyond boundaries, with the ease of association \\
\hline \multicolumn{2}{|c|}{$-5-4-3-2-1012345$} \\
\hline \multicolumn{2}{|l|}{ 7. Speech } \\
\hline $\begin{array}{l}\text { Impaired (broken up with pauses, stammered, cluttered, quite, } \\
\text { stuttered, etc.) }\end{array}$ & $\begin{array}{l}\text { Improved, but with a volume control problem (loud) and a } \\
\text { rapid rate }\end{array}$ \\
\hline \multicolumn{2}{|c|}{$-5-4-3-2-1012345$} \\
\hline \multicolumn{2}{|l|}{ 8. Emotions } \\
\hline Anxiety, fear, hopelessness, and despair & Happiness, delight, cheerfulness, excitement \\
\hline \multicolumn{2}{|c|}{$-5-4-3-2-1012345$} \\
\hline \multicolumn{2}{|l|}{ 9. Volition } \\
\hline $\begin{array}{l}\text { Weak, fraught with self-motivation problems, insecurity, and } \\
\text { inactivity }\end{array}$ & $\begin{array}{l}\text { Strong, fraught with self-confidence, commitment to succeed, } \\
\text { and self-management }\end{array}$ \\
\hline \multicolumn{2}{|c|}{$-5-4-3-2-1012345$} \\
\hline \multicolumn{2}{|l|}{ 10. Focus } \\
\hline Decreasing to low, with the ease of distraction effect & $\begin{array}{l}\text { Increasing to high, implies resistance to distraction and } \\
\text { enthusiasm }\end{array}$ \\
\hline \multicolumn{2}{|c|}{$-5-4-3-2-10012345$} \\
\hline \multicolumn{2}{|c|}{ PHYSIOLOGICAL REACTIONS } \\
\hline \multicolumn{2}{|l|}{ 11. Temperature sensation } \\
\hline Cold sensation in extremities, chills & $\begin{array}{l}\text { Warm sensation in extremities, general raise in body } \\
\text { temperature }\end{array}$ \\
\hline \multicolumn{2}{|c|}{$-5-4-3-2-10123345$} \\
\hline \multicolumn{2}{|l|}{ 12. Muscle tone } \\
\hline $\begin{array}{l}\text { Significant tension, hand tremor, twitching and tics (on the face, } \\
\text { around the lips, in the eyelids) }\end{array}$ & Moderate muscle tone and tension \\
\hline$-5-4-3-2$ & 12345 \\
\hline
\end{tabular}




\section{Motion coordination}

Coordination impairment (non-smooth movements, deformed handwriting, hand dexterity problems)

$-5-4-3-2-10123345$

\section{Motor activity}

Decreasing due to the lack of motivation to move and apathy (limitation in movement)

\section{$-5-4-3-2-1012345$}

\section{Cardiovascular sensations}

Unpleasant sensations in the heart (pain, feeling of squeezing in the chest)

$-5-4-3-2-10012345$

\section{Respiratory sensations}

Shortness of breath, feeling of lump in the throat, feeling of not being able to intake enough air

$-5-4-3-2-10123345$

\section{Perspiration}

Cold sweats, excessive sweating of the hands, palms, armpits, back, etc.

Insignificant sweating, relatively dry skin

$-5-4-3-2-100123445$

18. Sensations in the gastroenteric tract

Pain, the loss of appetite, nausea, thirst

Sensation of moderate hunger, occasional rumbling noises

$-5-4-3-2-10123345$

\section{Oral mucosa status}

Dry feeling in the mouth

Moderate increase in saliva secretion

$-5-4-3-2-1012345$

\section{Skin color}

Skin blanching (on the face, hands, and on the neck); change of color to marble in a mottled pattern

$-5-4-3-2-10012345$

\section{FEELINGS}

\section{Depression - Optimism}

21. Wistfulness

Cheerfulness

$-5-4-3-2-1012345$

22. Sadness

Optimism

$-5-4-3-2-10122345$

23. Sorrow Fervency

$-5-4-3-2-1012345$

Activity-Passivity

24. Inactivity

Activity

$-5-4-3-2-10012345$

25. Drowsiness Vivacity

$-5-4-3-2-1012345$

26. Fatigue Liveliness

$-5-4-3-2-1012345$

Intentionality

27. Negative

Positive

$-5-4-3-2-1012345$

Stress - Relaxation

28. Inhibition

Disinhibition

$-5-4-3-2-1012345$

29. Heavy feelings

Light feelings

$-5-4-3-2-1012345$

30. Restrainedness
Freedom

$-5-4-3-2-1012345$ 


\begin{tabular}{|c|c|}
\hline \multicolumn{2}{|c|}{ BEHAVIOR } \\
\hline 31. Non-initiative & Initiative \\
\hline \multicolumn{2}{|c|}{$-5-4-3-2-1012345$} \\
\hline 32. Non-driven & Driven \\
\hline \multicolumn{2}{|c|}{$-5-4-3-2-1012345$} \\
\hline 33. Impulsive & Non-impulsive \\
\hline \multicolumn{2}{|c|}{$-5-4-3-2-10123345$} \\
\hline 34. Spontaneous & Deliberte \\
\hline \multicolumn{2}{|c|}{$-5-4-3-2-10123345$} \\
\hline 35. Uncontrolled & Controlled \\
\hline \multicolumn{2}{|c|}{ 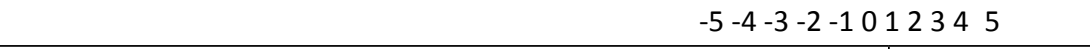 } \\
\hline 36. Non-consistent & Consistent \\
\hline \multicolumn{2}{|c|}{$-5-4-3-2-10123455$} \\
\hline 37. Distressed & Relaxed \\
\hline \multicolumn{2}{|c|}{$-5-4-3-2-1012345$} \\
\hline 38. Unsustainable & Sustainable \\
\hline \multicolumn{2}{|c|}{ 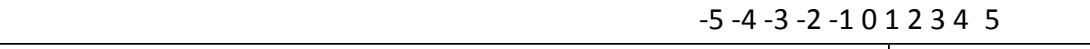 } \\
\hline 39. Insecure & Confident \\
\hline \multicolumn{2}{|c|}{$-5-4-3-2-10012345$} \\
\hline 40. Introverted & Extraverted \\
\hline \multicolumn{2}{|c|}{$-5-4-3-2-1012345$} \\
\hline
\end{tabular}

Conflict of interest: none declared Financial support: none declared

\section{REFERENCES}

1. Goldberg DJ. Facial rejuvenation. Practical medicine, Moscow; 2011.

2. American Society for Aesthetic Plastic Surgery (ASAPS) Cosmetic surgery national data bank statistics; 2014. Available from: http://www.surgery.org/sites/default/files/2014-Stats.pdf (update June 21, 2015).

3. International Society of Aesthetic Plastic Surgery (ISAPS). International survey on aesthetic/cosmetic procedures performed in 2014. Available from: http://www.isaps.org/ Media/Default/global-statistics/2015\%20ISAPS\%20Results. pdf (update July 13, 2015).

4. American Society for Dermatologic Surgery (ASDS) ASDS survey: Skin cancer, cosmetic procedures jump 22 percent in 2013. ASDS survey on dermatologic procedures; 2013. Available from: https://www.asds.net/_Media.aspx?id=7744 (update December 24, 2014).

5. Associazione Italiana Chirurgia Plastica Estetica (AICPE) Comunicati Stampa: Bellezza, i dati AICPE: Quasi un milione i trattamenti di medicina e chirurgia estetica eseguiti nel 2013. Available from: http://www.medicitalia.it/news/chirurgiaplastica-e-ricostruttiva/4829-dati-2013-chirurgia-medicinaestetica.html (update March 6, 2015).

6. BT-A. Instruction for Medical Use. Available from: www.rlsnet.ru (update January 9, 2019).

7. Sundaram H, Signorini M, Liew S, de Almeida ART, Wu Y, Braz AV, ... Group GAC. Global aesthetics consensus: botulinum toxin type Aevidence-based review, emerging concepts, and consensus recommendations for aesthetic use, including updates on complications. Plastic and reconstructive surgery 2016; 137(3): 518.

8. Phadke CP, Balasubramanian CK, Holz A, Davidson C, Ismail F, Boulias C. Adverse clinical effects of botulinum toxin intramuscular injections for spasticity. Canadian Journal of Neurological Sciences 2016; 43(2): 298-310.
9. Santamato A, Micello MF, Ranieri M, Valeno G, Albano A, Baricich A, ... Panza F. Employment of higher doses of botulinum toxin type A to reduce spasticity after stroke. Journal of the neurological sciences 2015; 350(1-2): 1-6.

10. Sansone RA, Sansone LA. Cosmetic surgery and psychological issues. Psychiatry (Edgmont) 2007; 4: 65-8.

11. Hall B. Treating the effects of bruxism with botulinum toxin type A: an overview. Journal of Aesthetic Nursing 2019; 8(3): 116-122.

12. Baumeister J-C, Papa G, Foroni F. Deeper than skin deep-The effect of botulinum toxin-A on emotion processing. Toxicon 2016; 118:86-90.

13. Yun YH, Kim TY, Lim TJ, Hwang YH, Choi IH. Narrative review and propose of thread embedding acupuncture procedure for facial wrinkles and facial laxity. The Journal of Korean Medicine Ophthalmology and Otolaryngology and Dermatology 2015; 28(1): 119-133.

14. Steinsapir KD, Rootman D, Wulc A, Hwang C. Cosmetic microdroplet botulinum toxin $A$ forehead lift: a new treatment paradigm. Ophthalmic Plastic \& Reconstructive Surgery 2015; 31(4): 263-268.

15. Coles N, Larsen J, Lench H. A meta-analysis of the facial feedback hypothesis literature. Open Science Framework 2017.

16. Lewis MB. The interactions between botulinum-toxin-based facial treatments and embodied emotions. Scientific reports 2018; 8(1): 14720.

17. Petrie T, Moore F. Facial Treatment With Botulinum Toxin Improves Attractiveness Rated by Self and Others, and Psychological Wellbeing. Dermatologic Surgery 2017; 43: S322-S328.

18. Volov VV. Phenomenon of face expression in psychology. Tomsk State University Journal 2014; 388: 211-218.

19. Izard CE. The Psychology of Emotions. Mastera Psikhologii Publihing House, St. Petersburg; 2012.

20. Ekman P. Emotions Revealed, Second Edition: Recognizing Faces and Emotions Life. Piter Publishers, St. Petersburg; 2012. 
21. Labunskaya VA. The language of not the body but the soul. Feniks Publishing House, Rostov-on-Don; 2009.

22. Nikolaeva NN. Characterless faces. Five major mistakes when using injection that reduce the attractiveness of the face. Inyektsionnyye metody v kosmetologii (Injection methods in cosmetology) 2018; 4: 28-34. (in Russian)

23. Malek N, Messinger D, Gao AYL, Krumhuber E, Mattson W, Joober $\mathrm{R}$, ... Martinez-Trujillo JC. Generalizing Duchenne to sad expressions with binocular rivalry and perception ratings. Emotion 2018; 19(2): 234-241.

24. Nikolaeva NN. The impact of cosmetic procedures on the quality of life of patients: a review of clinical cases. Kosmeticheskiye sredstva (Cosmetics) 2017; 2: 48-50. (in Russian)
25. Bleicher VM, Kruk IV. Explanatory dictionary of psychiatric terms. MODEK Publishers, Voronezh; 1995.

26. Wood A, Rychlowska M, Korb S, Niedenthal P. Fashioning the face: sensorimotor simulation contributes to facial expression recognition. Trends in cognitive sciences 2016; 20(3): 227-240.

27. Shafiei K, Sedighi B, Sherafat A. Facial emotion recognition after cosmetic botulinum toxin injection. Romanian Journal of Neurology 2018; 17(3).

28. Bowen KL, Morgan JE, Moore SC, van Goozen SHM. Young Offenders' Emotion Recognition Dysfunction Across Emotion Intensities: Explaining Variation Using Psychopathic Traits, Conduct Disorder and Offense Severity. J Psychopathol Behav 2014; 36: $60-73$. 